\title{
Strategies for treatment of childhood primary angiitis of the central nervous system
}

Jocelyne Beelen, BMSc, Susanne M. Benseler, MD, PhD, Anastasia Dropol, HBSc, Brianna Ghali, BSc, and Marinka Twilt, MD, PhD

Neurol Neuroimmunol Neuroinflamm 2019;6:e567. doi:10.1212/NXI.0000000000000567

\author{
Correspondence \\ Dr. Twilt \\ marinka.twilt@ \\ albertahealthservices.ca
}

\section{Abstract}

\section{Objective}

Childhood primary angiitis of the CNS (cPACNS) is a devastating neurologic disease. No standardized treatment protocols exist, and evidence is limited to open-label cohort studies and case reports. The aim of this review is to summarize the literature and provide informed treatment recommendations.

\section{Methods}

A scoping review of cPACNS literature from January 2000 to December 2018 was conducted using Ovid, MEDLINE, PubMed, Embase, Cochrane Database of Systematic Reviews, Cochrane Central Register of Controlled Trials, ClinicalTrials.gov, Vasculitis Foundation, European Vasculitis Society, CanVasc, Google Scholar, and Web of Science. Potentially relevant articles were selected for full-text review using the STROBE checklist if they met the following inclusion criteria: (1) reported treatment, (2) addressed pediatrics, (3) focused on the disease of interest, (4) included $\geq 5$ patients, (5) original research, and (6) full-length articles. Reviews, expert opinions, editorials, case reports with $<5$ patients, articles lacking treatment information, or non-English articles were excluded. A standardized assessment tool measured study quality. Treatment and outcomes were summarized.

\section{Results}

Of 2,597 articles screened, 7 studies were deemed high quality. No trials were available so no meta-analysis was possible. Overall, treatment strategies recommended are induction with acute antithrombotic therapy subsequently followed by high-dose oral prednisone taper over 3-12 months and long-term platelet therapy. In angiography-positive progressive-cPACNS and angiography-negative-cPACNS, we also recommend 6 months of IV cyclophosphamide therapy, with trimethoprim/sulfamethoxazole as part of induction, and maintenance therapy with mycophenolate mofetil/mycophenolic acid.

\section{Conclusion}

No grade-A evidence exists; however, this review provides recommendations for treatment of cPACNS. 


\section{Glossary}

AN = angiography-negative; APNP = angiography-positive nonprogressive; APP = angiography-positive progressive; ASA = aspirin; CA = conventional angiography; cPACNS = childhood primary angiitis of the CNS; DSA = digital subtraction angiography; IVMP = IV methylprednisolone; $\mathrm{MMF}=$ mycophenolate mofetil; $\mathrm{MRA}=$ magnetic resonance angiography; NASCET $=$ North American Symptomatic Carotid Endarterectomy Trial; PedsQL $=$ Pediatric Quality of Life; PGA = Physicians Global Assessment; PSOM = Pediatric Stroke Outcome Measure; vWF = von Willebrand factor.

Childhood primary angiitis of the CNS (cPACNS) is an increasingly recognized inflammatory brain disease. Previously healthy children present with severe neurologic deficits that, left untreated, could lead to devastating neurologic insult and even death. Early recognition and intervention with targeted therapy has led to better survival. The term PACNS was first coined by Calabrese for adults in $1988^{1}$ and has been adjusted for the pediatric population: patients $<18$ years of age presenting with a newly acquired focal or diffuse neurologic or psychiatric deficit without an underlying systemic disorder and evidence of vasculitis on angiography and/or histopathology. ${ }^{2}$

Classification of cPACNS is based on vessel size, with 3 subtypes recognized: angiography-positive nonprogressive (APNP) and angiography-positive progressive (APP) disease, affecting the large/medium-sized vessels, and angiography-negative (AN) disease, affecting small cerebral vessels. ${ }^{2,3}$ Children with APNPcPACNS typically present with a monophasic event consisting of focal neurologic deficits and evidence of ischemic stroke on MRI with corroborating angiography. ${ }^{2,45}$ Patients with APP-cPACNS present with both focal and diffuse neurologic deficits ${ }^{4,5}$ and progressive vessel narrowing on angiography beyond 3 months of disease. $^{2}$ In contrast, patients with AN-cPACNS exhibit normal angiography because of the difficulty in observing small vessels on digital subtraction angiography (DSA) or magnetic resonance angiography (MRA). ${ }^{6,7}$ However, MRI is frequently abnormal, characterized by multifocal inflammatory lesions not specific to any vessel distribution or territory. ${ }^{8,9}$ Thus, elective brain biopsy is mandated for diagnostic confirmation of AN-cPACNS.7,10 Children typically present with both focal and diffuse neurologic and psychiatric deficits together with seizures. ${ }^{3,4,7,9}$ The overall incidence of cPACNS remains unknown.

Similar to many other pediatric diseases, treatment is predominantly derived from adult PACNS literature. ${ }^{10,11}$ While therapeutic strategies for cPACNS have been described, they come largely from observational and open-label cohort studies because of the absence of randomized control trials and are not standardized across centers. To date, no scoping review of the pediatric literature on treatment of cPACNS has been performed. Therefore, in this review, we aim to describe the evidence and efficacy of treatment regimens reported in the pediatric literature.

\section{Methods}

\section{Search strategy and selection criteria}

A scoping review of the literature was conducted for the timeframe January 2000 to December 2018. Databases utilized in the search were Ovid, MEDLINE, PubMed, Embase, Cochrane Database of Systematic Reviews, Cochrane Central Register of Controlled Trials, ClinicalTrials.gov, Vasculitis Foundation, EUVAS (European Vasculitis Society), CanVasc, Google Scholar, and Web of Science. Searches were conducted with $\mathrm{MeSH}$ terms, including vasculitis, vasculitides, angiitis, angiitides, arteritis, central nervous system, CNS, brain, cerebral PACNS, pediatric, adolescent, child, and infant.

Studies were eligible if they met the following inclusion criteria: (1) treatment reported, (2) pediatric population addressed, (3) focused on disease of interest, cPACNS, (4) included $\geq 5$ patients, (5) original research, and (6) full-length articles. Only articles written in English were included. Reviews, expert opinions, editorials, case reports, and studies without treatment information were excluded. Studies were screened by perusing titles and abstracts for relative content. Articles deemed relevant were selected for full-text review and individually assessed for inclusion criteria using the STROBE checklist for cohort, case-control, and cross-sectional studies by 2 of 4 reviewers: J.B., A.D., B.G., and M.T. In case of conflicting evaluations, a third reviewer, S.M.B., was asked to make the final decision. Selected articles were assessed for quality. Studies reporting data on the same population were included individually and discussed together.

\section{Data analysis}

Quality was assessed through utilization of a modified version of Pasma et al. ${ }^{12}$ Quality Assessment Tool. Questions addressed patient recruitment through sampling method, participation, treatment and outcome measurements, and conflict declaration. Nonrelevant questions were dropped from the tool. Three questions were deemed essential: $>80 \%$ participation, reproducible treatment strategy, and reproducible outcome measure. A score of 1 was given to each question on satisfaction of both reviewers' assessment, with a maximum total score of 6 . A study with a total score of 4 or higher and at least 2 of 3 essential questions was considered high quality.

Studies were evaluated for design, location, sample size, and patient demographics. This information together with treatment strategies and outcomes was aggregated. Studies were compared by diagnostic subtype, treatment regimen, and outcomes. Acceptable study outcomes included mortality and neurologic outcome, preferably using the Pediatric Stroke Outcome Measure (PSOM) ${ }^{13}$ a determinant of neurologic 
dysfunction across 4 domains: sensorimotor, language production, language comprehension, and cognition/behavior.

\section{Role of funding source}

There was no funding source for this study. The corresponding authors had full access to all the data in the study and final responsibility for the decision to submit for publication.

\section{Data availability}

Data not provided in this article including comprehensive treatment and outcome summaries and search strategies are available to be shared by request.

\section{Results}

The search strategy identified a total of 2,596 articles, with 1 additional study identified by author MT (figure 1). Of 2,597 articles screened for title and abstract, 110 articles had full-text retrieval for assessment of inclusion criteria and 9 original articles were included for detailed analysis ${ }^{2,4,9,14-19}$ (figure 1). Reasons for article exclusion included: treatment description missing $(\mathrm{n}=24)$, exclusion of pediatric population $(\mathrm{n}=8)$, not PACNS $(n=5)$, case reports $<5$ children $(n=20)$, book chapters/reviews/editorials $(\mathrm{n}=39)$, and abstract only $(\mathrm{n}=$ 5 ). Seven studies were deemed high quality after quality assessment was conducted. Study characteristics are summarized in table. Of 9 studies reviewed, 4 described the same study population from Lahore, Pakistan ${ }^{16-19}$; 4 studies described the same population from Toronto, Canada ${ }^{2,4,9,14}$; and 1 reported a case series from Los Angeles, US. ${ }^{15}$

The Pakistani group ${ }^{16-19}$ identified children $<16$ years of age subsequently diagnosed with cPACNS at their center between January 2009 and December 2010. Diagnostic categorization was two-fold: based on stroke characteristics and cPACNS subtype. A total of 68 patients were identified: 50 presented with ischemic stroke, 10 with hemorrhagic stroke, and 8 with both ischemic and hemorrhagic lesions. Alternatively, 51 patients were classified as APNP-cPACNS and 17 as APPcPACNS. Diagnoses were based on conventional angiography (CA) and/or MRA in all patients.

Induction therapy, 3 days of IV methylprednisolone (IVMP), and/or IV immunoglobulin for 5 days with subsequent oral prednisone taper over 30 days, was completed by 56 patients. Patients with ischemic stroke also received IV heparin and subsequent oral anticoagulation therapy. Supplementary

Figure 1 Prisma 2009 flow diagram

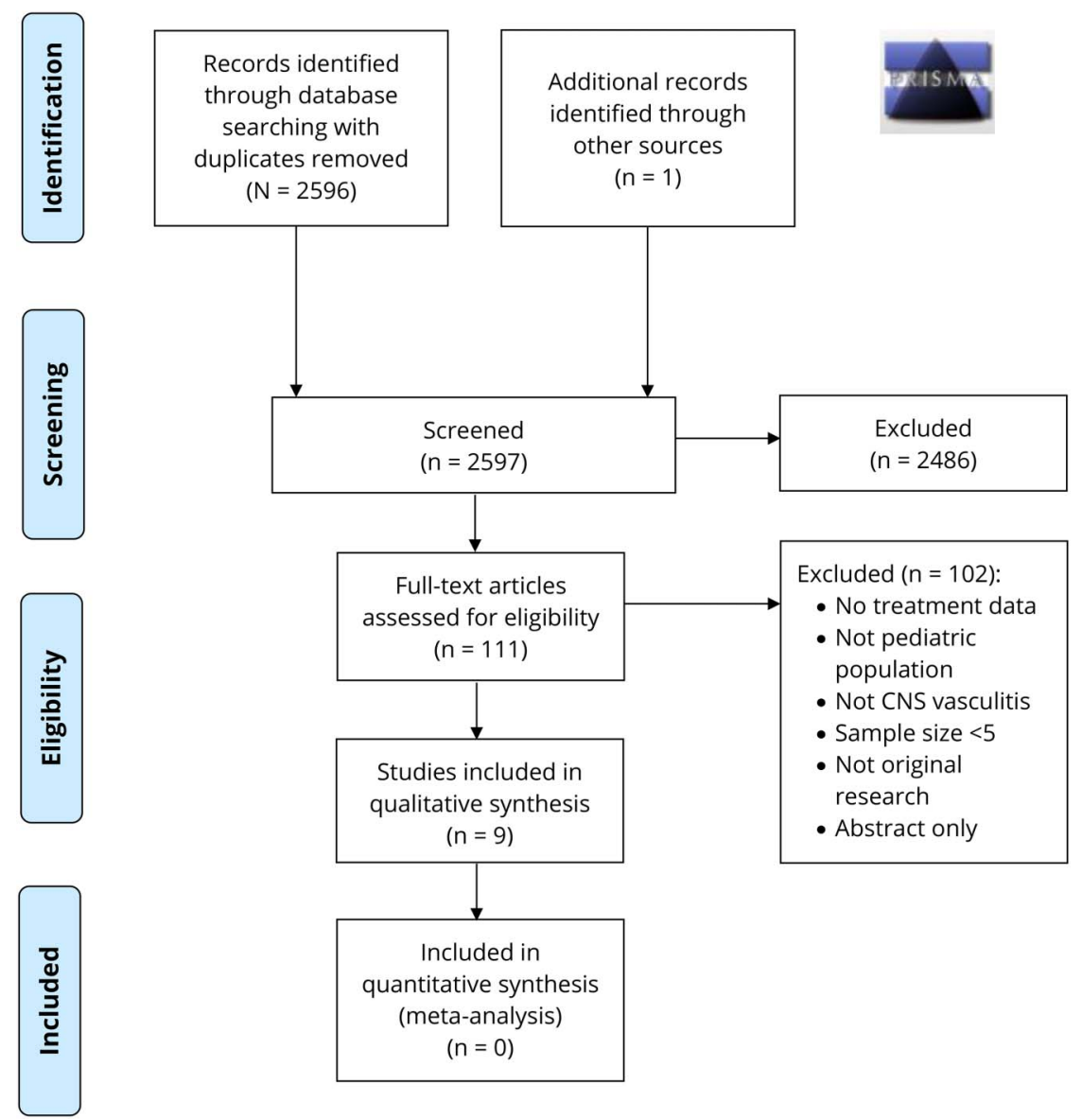


Table Summarized description of included studies

\begin{tabular}{|c|c|c|c|c|c|c|}
\hline Study & Diagnosis of CPACNS & Age (median y) & Treatment & & Outcome & \\
\hline \multirow[t]{5}{*}{$\begin{array}{l}\text { Malik } \\
\text { et al. }{ }^{19}\end{array}$} & ${ }^{\mathrm{a}} \mathrm{APP}(\mathrm{n}=17)$ & $7 \cdot 4(1 \cdot 5-16)$ & Induction therapy 5-10 D ( $n=56)$ & Maintenance therapy $24 \mathrm{M}(\mathrm{n}=56)$ & $\begin{array}{l}\text { Mortality at } \\
\text { discharge }(n=68)\end{array}$ & Neurologic examination at discharge $(n=56)$ \\
\hline & $\operatorname{APNP}(n=51)$ & & $\begin{array}{l}\text { IVMP } \pm \text { IVIG + oral prednisone + IV } \\
\text { heparin for ischemic infarct }\end{array}$ & ASA: 41 pts & Deceased: 12 pts & Normal: 11 pts \\
\hline & $\begin{array}{l}\text { APP and APNP diagnoses } \\
\text { based on CA and/or MRA } \\
\text { abnormalities }(n=68)\end{array}$ & & & ASA + AZA: 51 pts & Survived: 56 pts & Minor disabilities: 14 pts \\
\hline & & & & & & Moderate disabilities: 11 pts \\
\hline & & & & & & Severe disabilities: 20 pts \\
\hline \multirow[t]{10}{*}{$\begin{array}{l}\text { Malik } \\
\text { et al. }{ }^{17}\end{array}$} & ${ }^{\mathrm{a}} \mathrm{APP}(\mathrm{n}=17)$ & $7 \cdot 4(1 \cdot 5-16)$ & Induction therapy 5-10 D ( $n=56)$ & Maintenance therapy $24 \mathrm{M}(\mathrm{n}=56)$ & $\begin{array}{l}\text { Mortality at } \\
\text { discharge }(n=68)\end{array}$ & PSOM at discharge $(n=56)$ \\
\hline & $\operatorname{APNP}(n=51)$ & & $\begin{array}{l}\text { IVMP } \pm \text { IVIG + oral prednisone + IV } \\
\text { heparin for ischemic infarct }\end{array}$ & ASA: 40 pts & See Malik et al. ${ }^{19}$ & Normal: 11 pts \\
\hline & $\begin{array}{l}\text { APP and APNP diagnoses } \\
\text { based on CA and/or MRA } \\
\text { abnormalities }(n=68)\end{array}$ & & & ASA + AZA: 16 pts & $\begin{array}{l}\text { Mortality at follow- } \\
\text { up }(n=56)\end{array}$ & Minor disabilities: 14 pts \\
\hline & & & & & $\begin{array}{l}\text { Deceased: } 20 \\
\text { pts }\end{array}$ & Moderate disabilities: 11 pts \\
\hline & & & & & ASA: 15 pts & Severe disabilities: 20 pts \\
\hline & & & & & $\begin{array}{l}\text { ASA + AZA: } 5 \\
\text { pts }\end{array}$ & PSOM at follow-up (median $32 \mathrm{M})(\mathrm{n}=32)$ \\
\hline & & & & & $\begin{array}{l}\text { Relapse }{ }^{b} \text { at follow- } \\
\text { up }(n=56)\end{array}$ & Normal: 8 pts \\
\hline & & & & & $20 \mathrm{pts}$ & Minor disabilities: 10 pts \\
\hline & & & & & ASA: $18 / 40$ pts & Moderate disabilities: $10 \mathrm{pts}$ \\
\hline & & & & & $\begin{array}{l}\text { ASA + AZA: } 2 / \\
16 \text { pts }\end{array}$ & Severe disabilities: 4 pts \\
\hline \multirow[t]{2}{*}{$\begin{array}{l}\text { Malik } \\
\text { et al. }{ }^{18}\end{array}$} & ${ }^{\mathrm{a}} \mathrm{APP}(\mathrm{n}=17)$ & $7 \cdot 4(1 \cdot 5-16)$ & Acute anticoagulation therapy $(n=58)$ & Long-term therapy $(n=54)$ & $\begin{array}{l}\text { Mortality at } \\
\text { discharge }(n=68)\end{array}$ & Neurologic examination at discharge $(n=56)$ \\
\hline & $\operatorname{APNP}(n=51)$ & & IV heparin for ischemic infarct & ASA: 40 pts & See Malik et al. ${ }^{19}$ & See Malik et al. ${ }^{19}$ \\
\hline
\end{tabular}


Table Summarized description of included studies (continued)

\begin{tabular}{|c|c|c|c|c|c|c|}
\hline Study & Diagnosis of CPACNS & Age (median y) & Treatment & & Outcome & \\
\hline & $\begin{array}{l}\text { APP and APNP diagnoses } \\
\text { based on CA and/or MRA } \\
\text { abnormalities }(n=68)\end{array}$ & & & ASA + AZA: 14 pts & & \\
\hline $\begin{array}{l}\text { Alhaboob } \\
\text { et al. }{ }^{16}\end{array}$ & ${ }^{\mathrm{a}} \mathrm{APP}(\mathrm{n}=17)$ & $7 \cdot 4(1 \cdot 5-16)$ & Induction therapy 5-10 D $(n=56)$ & Maintenance therapy $24 M(n=56)$ & $\begin{array}{l}\text { Mortality at } \\
\text { discharge }(n=68)\end{array}$ & Neurologic examination at discharge $(n=56)$ \\
\hline & $\operatorname{APNP}(n=51)$ & & $\begin{array}{l}\text { IVMP } \pm \text { IVIG + oral prednisone + IV } \\
\text { heparin for ischemic infarct }\end{array}$ & ASA therapy: 41 pts & See Malik et al. ${ }^{19}$ & See Malik et al. ${ }^{19}$ \\
\hline & $\begin{array}{l}\text { APP and APNP diagnoses } \\
\text { based on CA and/or MRA } \\
\text { abnormalities }(n=68)\end{array}$ & & & ASA + AZA: 15 pts & & \\
\hline $\begin{array}{l}\text { Benseler } \\
\text { et al. }{ }^{2}\end{array}$ & $\operatorname{APP}(n=20)$ & $7 \cdot 17(0 \cdot 7-17 \cdot 6)$ & Acute antithrombotic therapy $(n=62)$ & $\begin{array}{l}\text { Long-term antithrombotic therapy + } \\
\text { steroids } \pm \text { IV cyclo }(n=22)\end{array}$ & Mortality ( $n=62)$ & $\begin{array}{l}\text { Complete neurologic recovery }{ }^{c} \text { on PSOM at } \\
\text { follow-up (mean } 20 \mathrm{M})(\mathrm{n}=22)\end{array}$ \\
\hline & $\operatorname{APNP}(n=42)$ & & $\begin{array}{l}\text { Long-term antithrombotic therapy }(\mathrm{n}= \\
\text { 40) }\end{array}$ & APP-cPACNS: 13 pts & 0 pts & APP-CPACNS: 9 pts \\
\hline & $\begin{array}{l}\text { APP and APNP diagnoses } \\
\text { based on MRA abnormalities } \\
(n=62) \text { and/or CA } \\
\text { abnormalities }(n=51)\end{array}$ & & APP-CPACNS: 7 pts & APNP-CPACNS: 9 pts & & APNP-CPACNS: 13 pts \\
\hline & & & APNP-CPACNS: 33 pts & & & \\
\hline $\begin{array}{l}\text { Hutchinson } \\
\text { et al. }\end{array}$ & AN $(n=19)$ & $9 \cdot 8(5 \cdot 5-17 \cdot 8)$ & Induction therapy $6 \mathrm{M}(\mathrm{n}=14)$ & Maintenance therapy $18 M(n=13)$ & Mortality $(n=19)$ & Good neurologic outcome ${ }^{d}$ on PSOM: \\
\hline & Confirmatory biopsy $(n=19)$ & & IV cyclo + oral prednisone & MMF or AZA + oral prednisone & 0 pts & $12 \mathrm{M}: 8 / 16$ pts \\
\hline & $\begin{array}{l}\text { Angiography methods } \\
\text { included: MRA, venography, } \\
\text { and CA }\end{array}$ & & & 7/9 pts AZA switched to MMF & & $24 \mathrm{M}: 9 / 13$ pts \\
\hline & $\begin{array}{l}\text { Confirmatory biopsy included } \\
\text { lesional/nonlesional } \\
\text { specimen and lymphocytic } \\
\text { vasculitis histology }\end{array}$ & & & & & \\
\hline $\begin{array}{l}\text { Cellucci } \\
\text { et al. }{ }^{4}\end{array}$ & $A P(n=14)$ & $9 \cdot 8(3 \cdot 3-17 \cdot 8)$ & ASA therapy $(n=14)$ & IV cyclo x 6 M \pm MMF or AZA $(n=27)$ & Mortality $(n=39)$ & Good neurologic outcome ${ }^{d}$ on PSOM: \\
\hline & AN $(n=25)$ & & AP-CPACNS & AP-CPACNS: 7 pts & 0 pts & $52 \%$ of patients at $12 \mathrm{mo}$ \\
\hline & $\begin{array}{l}\text { AP diagnosis based on CA } \\
\text { and/or MRA abnormalities } \\
(n=14)\end{array}$ & & Oral prednisone $2-6 \mathrm{M}$ or $12 \mathrm{M}(\mathrm{n}=38)$ & AN-CPACNS: 23 pts & $\begin{array}{l}\text { Flare during } \\
\text { follow-up }(n=39)\end{array}$ & $65 \%$ of patients at $24 \mathrm{mo}$ \\
\hline
\end{tabular}


Table Summarized description of included studies (continued)

\begin{tabular}{|c|c|c|c|c|c|c|}
\hline Study & Diagnosis of cPACNS & Age (median y) & Treatment & & Outcome & \\
\hline & $\begin{array}{l}\text { AN diagnosis based on brain } \\
\text { biopsy showing lymphocytic } \\
\text { vasculitis }(n=22)\end{array}$ & & APNP-CPACNS: 13 pts & 3 pts did not receive IV cyclo & $6 \mathrm{pts}$ & $\begin{array}{l}\text { Summary scores significantly decreased } \\
\text { over time }(p<0.001)\end{array}$ \\
\hline & $\begin{array}{l}\text { Those who did not undergo } \\
\text { brain biopsy had clinical } \\
\text { features, blood work, and } \\
\text { lumbar puncture consistent } \\
\text { with AN-CPACNS, and negative } \\
\text { microbiologic and } \\
\text { antineuronal investigations }\end{array}$ & & AN-cPACNS: 25 pts & No maintenance therapy $(n=2)$ & & \\
\hline \multirow{4}{*}{$\begin{array}{l}\text { Elbers } \\
\text { et al. }{ }^{14}\end{array}$} & $A P(n=27)$ & $7 \cdot 5(2-15)$ & Unfractionated heparin $(n=27)$ & Acute IVMP + oral steroid $(n=12)$ & Mortality & Stroke recurrence $(n=39)$ \\
\hline & Abnormal MRA $(n=25)$ & & Transitioned to warfarin: 5 pts & $\begin{array}{l}\text { Long-term immunosuppression }(n= \\
\text { 6) }\end{array}$ & $0 \mathrm{pts}$ & 4 pts \\
\hline & Abnormal DSA $(n=24)$ & & Transitioned to ASA: 17 pts & \pm ASA: 4 pts & & \\
\hline & $\begin{array}{l}\text { Abnormal DSA was found in } \\
\text { the } 2 \text { patients with normal } \\
\text { MRA }\end{array}$ & & Transitioned off heparin: 1 pt & MMF: 2 pts & & \\
\hline \multirow[t]{4}{*}{$\begin{array}{l}\text { Gallagher } \\
\text { et al. }{ }^{15}\end{array}$} & AP $(n=5)$ & $8(5-11)$ & Induction therapy $(n=5)$ & Maintenance therapy $(n=3)$ & Mortality $(n=5)$ & $\begin{array}{l}\text { Clinical/radiologic evaluation at last follow- } \\
\text { up }(n=5)\end{array}$ \\
\hline & $\begin{array}{l}\text { AP diagnosis based on MRA } \\
\text { abnormalities }(n=3) \text { and/or } \\
\text { CA abnormalities }(n=4)\end{array}$ & & $\begin{array}{l}\text { Oral prednisone } \pm \text { IVMP } \pm \\
\text { anticoagulation + IV cyclo }\end{array}$ & Methotrexate or AZA $\pm \mathrm{ASA}$ & $0 \mathrm{pts}$ & Asymptomatic: 3 pts \\
\hline & & & & & & Lost to follow-up: $1 \mathrm{pt}$ \\
\hline & & & & & & Residual deficits: $1 \mathrm{pt}$ \\
\hline
\end{tabular}

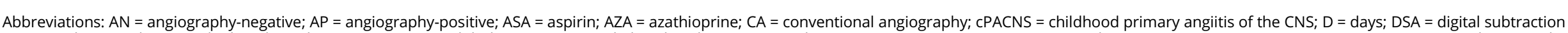

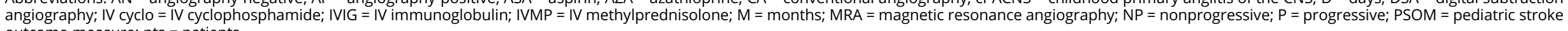

outcome measure; pts $=$ patients.
a Also described as ischemic stroke $(n=50)$, hemorrhagic stroke $(n=10)$, and both $(n=8)$.

${ }^{\mathrm{b}}$ Relapse defined as emergence of signs and symptoms of stroke confirmed with neuroimaging of brain after remission.

c Complete neurologic recovery defined as neurologic deficit severity score of 0 .

${ }^{\mathrm{d}}$ Good neurologic outcome defined as $\leq 0.5$ across any domain. 
calcium and vitamin D were prescribed with anticonvulsants, antipsychotics, antibiotics, antivirals, and antacids as needed. A total of 12 patients died before completing induction therapy from complications involving cerebral artery and/or parenchymal bleeding. The remaining 41 patients were allocated to 24 months of maintenance therapy consisting of either aspirin (ASA) daily for ischemic stroke or together with daily azathioprine for progressive arteriopathies. Despite a clearly delineated therapeutic regimen, the Pakistani group reported conflicting data in regard to the number of patients assigned to each therapy across the 4 studies. Both the initial study by Malik et al. ${ }^{19}$ and Alhaboob et al. ${ }^{16}$ identified 41 patients assigned to ASA alone and 15 patients to ASA together with azathioprine for 24 months. However, Malik et al. ${ }^{17}$ indicated that 40 patients were assigned to the 24 months ASA only group, and 16 patients to ASA and azathioprine, with ASA duration increased to 60 months in this study. Malik et al. ${ }^{18}$ did not provide details of induction therapy, only that ischemic infarcts were initially treated with IV heparin. From this group, 40 patients were discharged on ASA for 24 months and 14 received adjunctive azathioprine therapy.

The Pakistani group reported mortality and morbidity across different intervals. Remission was described as a complete absence of disease activity in clinical symptoms, exam findings, lab markers, and imaging for at least 3 months, and relapse was defined as an emergence of signs/symptoms of stroke confirmed by neuroimaging (CA and/or MRA) after remission. All 4 studies documented mortality at discharge in 12 patients $(17 \cdot 6 \%)$. Malik et al. ${ }^{17-19}$ reported clinical state at time of discharge for all survivors, defined as neurologic assessment for motor, visual, and/or speech difficulties. Normal examination was reported in 11 (20\%), minor disability in $14(25 \%)$, moderate disability in 11 $(20 \%)$, and severe disability in $20(35 \%)$ patients. Malik et al. ${ }^{15}$ described relapse in a total of 30 patients (54\%) during maintenance therapy. From the ASA only group, 18 patients (45\%) relapsed within the first 24 months, which resulted in 10 deaths, and of the remaining 22 patients (55\%) who completed ASA therapy, 5 relapsed and 5 died. Overall mortality in the ASA group was $15 / 40$ (38.5\%). Of the 16 patients on maintenance with ASA and azathioprine, 2 patients (13\%) relapsed within 24 months and both survived. The number of deaths reported was 5 (31\%): 3 patients died from massive cerebral hemorrhage, and 2 of 3 patients died after relapse within 6 months of successfully completing therapy. Therefore, the overall mortality during maintenance reported by Malik et al. ${ }^{17}$ at a medium followup of 34 months was $20(35 \cdot 7 \%)$ of the initial 56 survivors, either as a direct result or as a complication of first or second relapse, with 5 deaths reportedly due to non-cPACNS causes. Malik et al. ${ }^{17}$ also reported the outcome at last follow-up using the PSOM. ${ }^{13}$ From the 32 patients assessed: 8 (25\%) a normal outcome, $10(31 \%)$ minor disabilities, 10 (31\%) moderate disabilities, $4(13 \%)$ severe disabilities, and 4 patients were lost to follow-up.
The Canadian studies ${ }^{2,4,9,14}$ similarly identified patients from the same center, though each study varied in sample size and diagnostic subtype. Benseler et al. ${ }^{2}$ identified 62 children $<18$ years of age between January 1990 to December 2002 diagnosed with AP-cPACNS: 42 APNP-cPACNS and 20 APPcPACNS. Diagnoses were based on MRA and/or CA abnormalities.

All patients received antithrombotic therapy with ASA, heparin, or warfarin. A total of 41 patients $(65 \%)$ continued with this treatment approach long-term: 33 patients with APNPcPACNS and 7 patients with APP-cPACNS. In contrast, 22 patients (35\%) received immunosuppressive intervention with steroids alone or a combination of steroids and IV cyclophosphamide: 9 (41\%) APNP-cPACNS and 13 (59\%) APP-cPACNS. Benseler et al. ${ }^{2}$ measured outcome at last evaluation (mean 20 months) as complete neurologic recovery, defined as neurologic deficit severity score of 0 on PSOM; any other deficit severity score was defined as incomplete recovery. A total of 22 patients (35\%) made a complete neurologic recovery: 13 (31\%) of APNP-cPACNS and $9(45 \%)$ of APP-cPACNS. No deaths were reported.

Hutchinson et al. ${ }^{9}$ identified 19 patients $<18$ years of age with AN-cPACNS diagnosis between January 2002 and December 2009. MRA, venography, and CA were used. Diagnosis in all patients was based on a confirmatory biopsy. Patients received induction and maintenance therapy for 24 months. Induction therapy was defined as 6 months of IV cyclophosphamide monthly, together with Pneumocystis jiroveci pneumonia prophylaxis, oral prednisone daily, supplementary calcium, vitamin D, and anticonvulsants/antipsychotics as needed. Thirteen patients (68\%) completed induction and went on to maintenance therapy. Maintenance consisted of an additional 18 months of therapy, with 5 patients (35\%) assigned to mycophenolate mofetil (MMF) and $9(65 \%)$ assigned to azathioprine with anticonvulsants/antipsychotics as needed. Seven $(78 \%)$ of 9 patients on azathioprine switched to MMF because of treatment failure or intolerance. Only 5 patients (36\%) completed maintenance therapy and were taken off medication. Primary outcome was assessed on PSOM at 24 months, with good outcome defined as a score of $\leq 0.5$ across each of the 4 domains. Secondary outcomes included treatment efficacy and safety, determined by PSOM at 12 months and final follow-up, disease flare, and discontinuation of immunosuppressants. Good neurologic outcome on PSOM at 12 months was reported in $8(50 \%)$ of 16 patients and 9 (70\%) of 13 at final follow-up. Disease flare during treatment was described in 8 patients (42\%): $2 / 19$ (11\%) during induction, $5 / 14$ (36\%) during maintenance, and 1/5 (20\%) off medication. No patients relapsed on MMF. Of 5 patients who completed maintenance therapy, 4 achieved remission, defined as complete absence of disease activity in clinical symptoms, examination findings, lab markers, and imaging for at least 3 months. Safety was determined by mortality, serious infection, and each of cataracts, avascular necrosis, vertebral fractures, or type II diabetes mellitus. No patients in this study 
died; however, 2 were reported to have had a serious infection requiring hospital admission; 1 developed cataracts, 1 avascular necrosis, and 3 with vertebral fractures. No diabetes mellitus was reported. Pediatric Quality of Life (PedsQL) ${ }^{20}$ was reported for both child and parent at final follow-up, together with cognitive outcome testing by the Weschler Intelligence Scale for Children IV and Weschler Adult Intelligence Scale III at 14 months postdiagnosis. Abnormal scores were defined as any index scores that were $\geq 1$ SDs below the mean of the normative sample. The PedsQL questionnaire was completed by 17 patients and 15 parents: median physical score was 78 (range $=0-100$ ) for children and 66 (range $=9-100$ ) for parents, and median psychosocial score 73 (range $=27-100$ ) for children and 63 (range = 37-100) for parents. Cognitive outcome was assessed in 10 children: Full Scale Intelligence Quotient was reported as abnormal in $8(80 \%)$, working memory in all $10(100 \%)$, verbal comprehension in $7(70 \%)$, perceptual reasoning in 6 (60\%), and processing speed in 5 (50\%).

Cellucci et al. ${ }^{4}$ identified 39 patients $<18$ years of age between June 2001 and October 2010 diagnosed with cPACNS: 14 APcPACNS, not further subdivided, and 25 AN-cPACNS. APcPACNS diagnosis was based on CA and/or MRA $(n=14)$. AN-cPACNS diagnosis was based on confirmatory biopsy in 22 patients. Patients without biopsy had features, blood work, and lumbar puncture consistent with AN-cPACNS. Some patients with AP-cPACNS were also represented in the Benseler et al. ${ }^{2}$ study and in the Hutchinson et al. ${ }^{9}$ study.

All 14 patients with AP-cPACNS received ASA, and 9 (64\%) received additional anticoagulation with unfractionated/lowmolecular weight heparin for 2 months. High-dose prednisone was prescribed in all but 1 patient with AP-cPACNS, with a varied tapering schedule: 2-6 months in 6 patients (46\%) and 12 months in 7 (54\%). IV cyclophosphamide over 6 months followed by MMF or azathioprine was given to a further 7 patients (54\%) with AP-cPACNS; 1 patient with AP-cPACNS received anticoagulation therapy only. Highdose prednisone with 12-months taper was prescribed in all patients with AN-cPACNS. IV cyclophosphamide for 6 months in combination with azathioprine or MMF was reported in 20 patients ( $80 \%$ ) with AN-cPACNS, while azathioprine or MMF alone as induction/maintenance therapy was described in 3 patients (12\%) with AN-cPACNS. Two patients (8\%) with AN-cPACNS did not receive therapy. Outcomes were reported serially across 24 months and included disease activity as measured by the Physicians Global Assessment (PGA), a visual analog scale with a score of zero indicating no disease activity and 10 indicating severe activity; von Willebrand factor (vWF) antigen levels where high numbers indicate high disease activity with $>1.40 \mathrm{IU} / \mathrm{mL}$ being considered abnormal; and neurologic outcome on PSOM with good outcome defined as a score of $\leq 0.5$ across each domain. Disease activity was elevated at time of diagnosis, but significantly decreased over time in all patients $(p<0.001)$. vWF antigen levels decreased over time $(p<$
0.001). PSOM summary scores decreased significantly over time $(p<0.001)$, with $52 \%$ of patients having a good neurologic outcome at 12 months, and $65 \%$ at 24 months. A total of $6(15 \%)$ developed disease flare during follow-up defined as an increase in PGA by at least $1 \mathrm{~cm}$ in presence of recurrent symptoms, laboratory changes, and/or MRI findings. No patients died.

Elbers et al. ${ }^{14}$ described 27 patients $<18$ years of age with APcPACNS diagnosed between January 1998 and December 2013. Diagnosis was based on MRA and DSA abnormalities. Patients might overlap with the Benseler et al. ${ }^{2}$ and Cellucci et al. $^{4}$ studies. Acute treatment with unfractionated heparin was described in 23 patients (85\%): 5 subsequently transitioned to warfarin, 17 to ASA, and none in 1. ASA alone, or with immunosuppression, was described in the remaining 4 patients. Two patients received chronic immunosuppression with MMF and 1 received plasmapheresis. IVMP together with a 3-month oral steroid taper was described in 12 patients, with no long-term immunosuppression. An additional 7 patients were treated with acyclovir. Outcomes included vascular imaging at 12 months, assessed using the North American Symptomatic Carotid Endarterectomy Trial (NASCET) criteria and described as improved (normal angiography, improved flow, or fewer abnormal vessels), stable (no change in flow abnormality or number of involved vessels), or worsened (involvement of new vessels or worsening of an existing flow abnormality by at least 1 point on follow-up imaging), and possibly discordant (worsened patients where a new or worsening arterial abnormality coexisted with an improved or normalized vessel), as well as stroke recurrence. The NASCET criteria scores vessel narrowing from 1 to 4 progressing from normal (0\%-9\%), to mild (10\%-29\%), moderate $(30 \%-69 \%)$, and severe stenosis $(70 \%-99 \%)$ or complete occlusion (no flow detected). A total of 10 (37\%) patients were described as improved, 4 of which received steroids as treatment; 6 (22\%) as stable, 2 of which received steroids; and 11 (41\%) worsened with 7 described as discordant, 6 of which received steroids. Stroke recurrence was reported in 4 patients (15\%). No patients died.

Gallagher et al. ${ }^{15}$ described 5 cases of AP-cPACNS at their center with no fixed treatment regimen. Diagnosis was based on MRA and/or CA abnormalities. Two patients were treated with IVMP, either at their first or subsequent disease presentation. All patients received IV cyclophosphamide; however, 1 discontinued after the first infusion due to intolerance. All patients received oral prednisone of varying doses; 2 received short-term ( $<6$ months) steroid therapy, 2 remained on oral steroids long-term ( $>6$ months), and 1 was lost to follow-up after 6 months. One patient received long-term treatment with azathioprine and 2 with methotrexate. Four ( $80 \%)$ of the 5 patients received anticoagulation therapy with either ASA or warfarin during their illness. No validated outcome measures were used to assess outcomes for these patients; however, at last follow-up, 3 patients were reported as neurologically asymptomatic, 1 had mild residual deficits, 
and 1 was lost to follow-up but continued on treatment at their last documented visit.

\section{Discussion}

This is the first scoping review of treatment in cPACNS. Despite the paucity of randomized clinical trials, evidence in the literature offers support for treatment strategies. For APNP-cPACNS, the authors recommend treatment with long-term antiplatelet therapy to reduce the risk of stroke relapse and mortality as reported in the Pakistani cohort. ${ }^{16-19}$ The authors concur with CNS vasculitis expert opinion in recommending short-term immunosuppressive with IVMP and acute antithrombotic therapy, subsequently followed by

Figure 2 Recommended treatment protocol

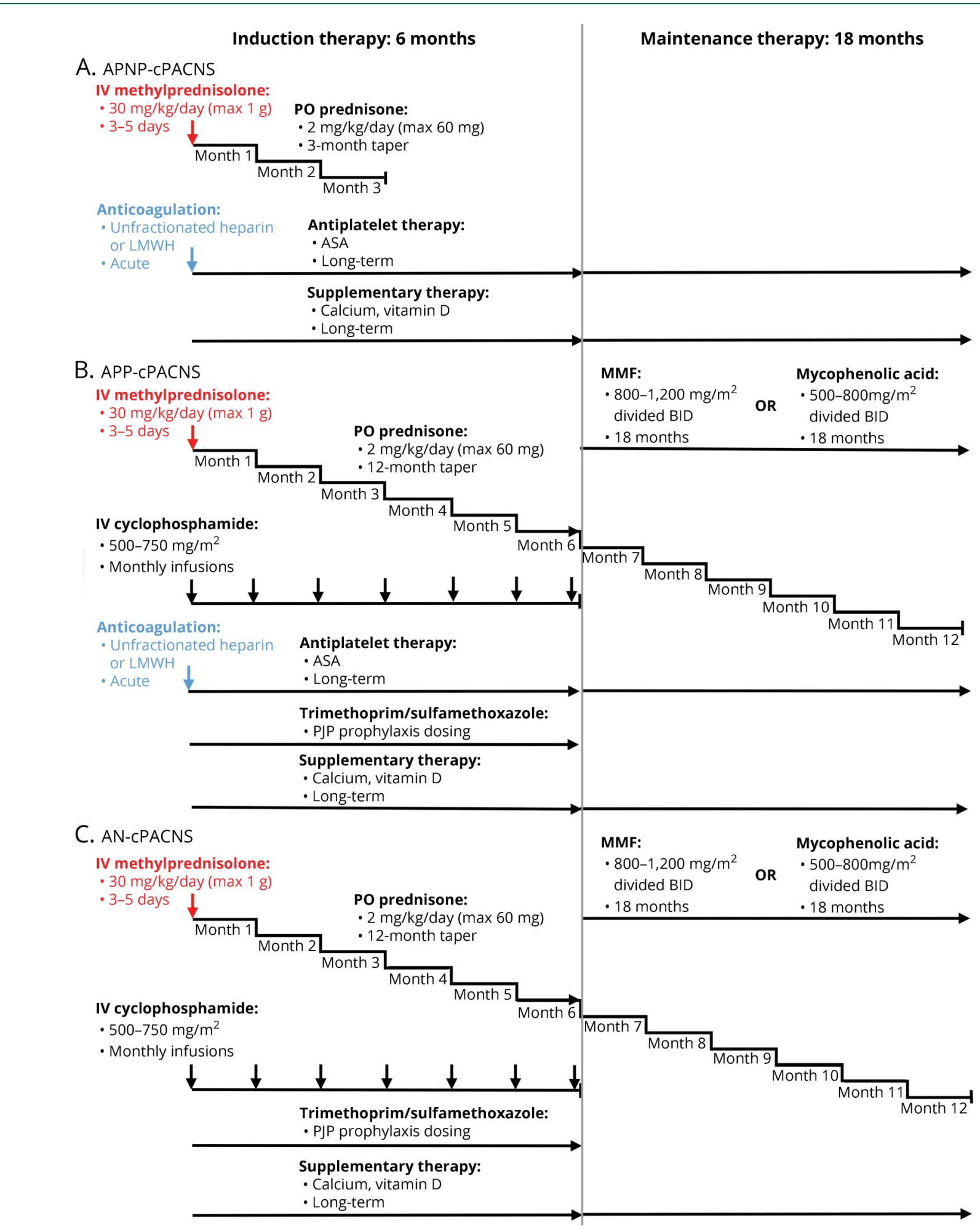


high-dose oral prednisone (figure 2A).,10,21-23 In APPcPACNS, the authors support a combination of anticoagulation and induction therapy, with both IV steroids and IV cyclophosphamide with steroid taper (figure $2 B$ ) 3,4,15-19 to increase the prospect of neurologic recovery. ${ }^{3,10,15,21-26}$ Induction therapy for AN-cPACNS should similarly consist of IV steroids and IV cyclophosphamide (figure 2C). Evidence in the literature ${ }^{9,10,21-24}$ for long-term maintenance therapy in APP-cPACNS and AN-cPACNS supports daily MMF/ mycophenolic acid in preference to azathioprine to avoid the possibility of treatment failure or intolerance, as reported by Hutchinson et al. ${ }^{9}$ and the Pakistani group (figures $2 \mathrm{~B}$, 2C). ${ }^{16-19}$

In refractory disease, Batthish et al. ${ }^{25}$ reported successful use of infliximab therapy in treating 2 cases of AN-cPACNS with good control of inflammation and subsequent prevention of brain damage. Rosati et al. ${ }^{26}$ recently published a case series of 4 patients with AP-cPACNS successfully treated with longterm MMF. All revealed subsequent stability or improvement on MRI/MRA with no progression of arterial disease, and no relapses were reported in the follow-up period (range 10-42 months). ${ }^{26}$ Sen et al. ${ }^{24}$ also report successful maintenance treatment with MMF in 3 cases of cPACNS that had failed methotrexate or azathioprine and steroid treatment alone. No patients were reported to have had recurring symptoms, side effects, or new lesions on MRI. ${ }^{24}$

While this review provided a comprehensive review of treatment literature in CPACNS, there were several limitations. Based on our quality assessment definition for Q4, a minimum of 1 reproducible reported outcome was sufficient to satisfy outcome reproducibility. Many studies satisfied this criterion by reporting mortality, despite a lack of or irreproducibility of supplementary outcomes. Furthermore, using a validated measure like the PSOM was sufficient to satisfy the Q5 requirement. While the Pakistani group utilized the PSOM in outcome assessment, the lack of outcome definitions led to difficulty in result generalizability. Finally, while the same patient cohort was included in all 4 Pakistani group studies and treatment regimens were well described, the number of patients reported to each treatment arm was grossly inconsistent and calculated incorrectly. Despite these contradictions, the studies sufficiently satisfied the reproducible treatment criterion and were consequently rated high quality. Therefore, the authors believe that the quality assessment for a number of studies reviewed is overstated; were these studies to be rescored retrospectively, they would be deemed low quality. Finally, the case series by Gallagher et al., ${ }^{15}$ despite meeting inclusion criteria, only described case reports with inconsistent treatment regimens and lacked validated outcome measures.

In conclusion, available literature on treatment in cPACNS were thoroughly reviewed and findings summarized. Based on the evidence and current expert opinion, the authors provide recommendations for $\mathrm{CPACNS}$ treatment strategies. Rapid initiation with the recommended therapeutic interventions would serve to optimize survival and prevent permanent brain injury in patients with cPACNS to achieve the best possible outcome.

\section{Acknowledgment}

The authors would like to thank librarian Rachel Zhao for her contribution to the development and application of the search strategy.

\section{Study funding}

No targeted funding.

\section{Disclosure}

J. Beelen reports no disclosures; S. Benseler serves on the editorial board for Neurology: Neuroimmunology \& Neuroinflammation; A. Dropol, B. Ghali, and M. Twilt reports no disclosures. Go to Neurology.org/NN for full disclosures.

\section{Publication history}

Received by Neurology: Neuroimmunology \& Neuroinflammation January 24, 2019. Accepted in final form March 4, 2019.

\begin{tabular}{|c|c|c|c|}
\hline Name & Location & Role & Contribution \\
\hline $\begin{array}{l}\text { Jocelyne } \\
\text { Beelen, } \\
\text { BMSc }\end{array}$ & $\begin{array}{l}\text { Cumming School of } \\
\text { Medicine, University } \\
\text { of Calgary, Calgary }\end{array}$ & Author & $\begin{array}{l}\text { Evaluated literature; } \\
\text { compiled the data; } \\
\text { drafted the manuscript; } \\
\text { completed manuscript } \\
\text { revisions }\end{array}$ \\
\hline $\begin{array}{l}\text { Susanne } \\
\text { Benseler, } \\
\text { MD, PhD }\end{array}$ & $\begin{array}{l}\text { Alberta Children's } \\
\text { Hospital, University } \\
\text { of Calgary, Calgary }\end{array}$ & Author & $\begin{array}{l}\text { Conceptualized the } \\
\text { paper; revised the paper } \\
\text { critically for intellectual } \\
\text { content }\end{array}$ \\
\hline $\begin{array}{l}\text { Anastasia } \\
\text { Dropol, } \\
\text { HBSc }\end{array}$ & $\begin{array}{l}\text { Cumming School of } \\
\text { Medicine, University } \\
\text { of Calgary, Calgary }\end{array}$ & Author & $\begin{array}{l}\text { Conceptualized the } \\
\text { paper; evaluated the } \\
\text { literature; compiled } \\
\text { the data; drafted the } \\
\text { manuscript }\end{array}$ \\
\hline $\begin{array}{l}\text { Brianna } \\
\text { Ghali, Bsc }\end{array}$ & $\begin{array}{l}\text { University of } \\
\text { Calgary, Calgary }\end{array}$ & Author & $\begin{array}{l}\text { Completed the literature } \\
\text { search; evaluated the } \\
\text { literature; revised the } \\
\text { paper critically for } \\
\text { intellectual content }\end{array}$ \\
\hline $\begin{array}{l}\text { Marinka } \\
\text { Twilt, MD, } \\
\text { PhD }\end{array}$ & $\begin{array}{l}\text { Alberta Children's } \\
\text { Hospital, University } \\
\text { of Calgary, Calgary }\end{array}$ & Author & $\begin{array}{l}\text { Conceptualized the } \\
\text { paper; completed the } \\
\text { literature search; } \\
\text { evaluated the literature; } \\
\text { revised the paper } \\
\text { critically for intellectual } \\
\text { content }\end{array}$ \\
\hline
\end{tabular}

\section{References}

1. Calabrese LH, Mallek JA. Primary angiitis of the central nervous system. Report of 8 new cases, review of the literature, and proposal for diagnostic criteria. Medicine (Baltimore) 1988;67:20-39.

2. Benseler SM, Silverman E, Aviv RI, et al. Primary central nervous system vasculitis in children. Arthritis Rheum 2006;54:1291-1297.

3. Benseler SM, deVeber G, Hawkins C, et al. Angiography-negative primary central nervous system vasculitis in children: a newly recognized inflammatory central nervous system disease. Arthritis Rheum 2005;52:2159-2167.

4. Cellucci T, Tyrrell PN, Sheikh S, Benseler SM. Childhood primary angiitis of the central nervous system: identifying disease trajectories and early risk factors for persistently higher disease activity. Arthritis Rheum 2012;64:1665-1672. 
5. Cellucci T, Tyrrell PN, Twilt M, Sheikh S, Benseler SM. Distinct phenotype clusters in childhood inflammatory brain diseases: implications for diagnostic evaluation. Arthritis Rheumatol 2014;66:750-756.

6. Splendiani A, Catalucci A, Limbucci N, Turner M, Krings T, Gallucci M. Pediatric inflammatory diseases: part III: small vessels vasculitis. Neuroradiol J 2012;25: 715-724.

7. Elbers J, Halliday W, Hawkins C, Hutchinson C, Benseler SM. Brain biopsy in children with primary small-vessel central nervous system vasculitis. Ann Neurol 2010;68:602-610.

8. Aviv RI, Benseler SM, DeVeber G, et al. Angiography of primary central nervous system angiitis of childhood: conventional angiography versus magnetic resonance angiography at presentation. AJNR Am J Neuroradiol 2007;28:9-15.

9. Hutchinson C, Elbers J, Halliday W, et al. Treatment of small vessel primary CNS vasculitis in children: an open-label cohort study. Lancet Neurol 2010;9:1078-1084

10. Twilt M, Benseler SM. The spectrum of CNS vasculitis in children and adults. Nat Rev Rheumatol 2011;8:97-107.

11. Salvarani C, Brown RD Jr, Calamia KT, et al. Primary central nervous system vasculitis: analysis of 101 patients. Ann Neurol 2007;62:442-451.

12. Pasma A, van't Spijker A, Hazes JM, Busschbach JJ, Luime JJ. Factors associated with adherence to pharmaceutical treatment for rheumatoid arthritis patients: a systematic review. Semin Arthritis Rheum 2013;43:18-28.

13. Kitchen L, Westmacott R, Friefeld S, et al. The pediatric stroke outcome measure: a validation and reliability study. Stroke 2012;43:1602-1608.

14. Elbers J, Armstrong D, Yau I, Benseler S. Vascular imaging outcomes of childhood primary angiitis of the central nervous system. Pediatr Neurol 2016;63:53-59.

15. Gallagher KT, Shaham B, Reiff A, et al. Primary angiitis of the central nervous system in children: 5 cases. J Rheumatol 2001;28:616-623.
16. Alhaboob AA, Hasan GM, Malik MA, Rehman MZ. Therapeutic benefits and side effects of Azathioprine and Aspirin in treatment of childhood primary arterial stroke. Ann Neurosci 2014;21:10-13.

17. Malik MA, Ahmad N, Malik H. Maintenance treatment of childhood primary angiitis of central nervous system with spirin and azathioprine. Pediatr Ther 2013;3:174-179.

18. Malik MA, Choudry GR, Malik H. Recurrence prevention of childhood primary angiitis of central nervous system by combination of azathioprine and aspirin. Am J Med Stud 2013;1:22-27.

19. Malik MA, Zia-ur-Rehman M, Nadeem MM, et al. Childhood primary angiitis of the central nervous system. J Coll Physicians Surg Pak 2012;22:570-574.

20. Varni JW, Burwinkle TM, Seid M, Skarr D. The PedsQL 4.0 as a pediatric population health measure: feasibility, reliability, and validity. Ambul Pediatr 2003;3:329-341.

21. Twilt M, Benseler SM. Childhood inflammatory brain diseases: pathogenesis, diagnosis and therapy. Rheumatology (Oxford) 2014;53:1359-1368.

22. Gowdie P, Twilt M, Benseler SM. Primary and secondary central nervous system vasculitis. J Child Neurol 2012;27:1448-1459.

23. Moharir M, Shroff M, Benseler SM. Childhood central nervous system vasculitis. Neuroimaging Clin N Am 2013;23:293-308.

24. Sen ES, Leone V, Abinun M, et al. Treatment of primary angiitis of the central nervous system in childhood with mycophenolate mofetil. Rheumatology (Oxford) 2010;49: 806-811.

25. Batthish M, Banwell B, Laughlin S, et al. Refractory primary central nervous system vasculitis of childhood: successful treatment with infliximab. J Rheumatol 2012;39: 2227-2229.

26. Rosati A, Cosi A, Basile M, et al. Mycophenolate mofetil as induction and long-term maintaining treatment in childhood: primary angiitis of the central nervous system. Joint Bone Spine 2017;84:353-356. 


\title{
Neurology \\ Neuroimmunology \& Neuroinflammation
}

\author{
Strategies for treatment of childhood primary angiitis of the central nervous system \\ Jocelyne Beelen, Susanne M. Benseler, Anastasia Dropol, et al. \\ Neurol Neuroimmunol Neuroinflamm 2019;6; \\ DOI 10.1212/NXI.0000000000000567
}

This information is current as of May 3, 2019

\section{Updated Information \& Services}

References

Subspecialty Collections

Permissions \& Licensing

Reprints including high resolution figures, can be found at:

http://nn.neurology.org/content/6/4/e567.full.html

This article cites 26 articles, 3 of which you can access for free at: http://nn.neurology.org/content/6/4/e567.full.html\#\#ref-list-1

This article, along with others on similar topics, appears in the following collection(s):

All Pediatric

http://nn.neurology.org//cgi/collection/all_pediatric

Autoimmune diseases

http://nn.neurology.org//cgi/collection/autoimmune_diseases

Pediatric stroke; see Cerebrovascular Disease/ Childhood stroke http://nn.neurology.org//cgi/collection/pediatric_stroke_see_cerebrovas cular_disease-childhood_stroke

Vasculitis

http://nn.neurology.org//cgi/collection/vasculitis

Information about reproducing this article in parts (figures,tables) or in its entirety can be found online at:

http://nn.neurology.org/misc/about.xhtml\#permissions

Information about ordering reprints can be found online:

http://nn.neurology.org/misc/addir.xhtml\#reprintsus

Neurol Neuroimmunol Neuroinflamm is an official journal of the American Academy of Neurology.

Published since April 2014, it is an open-access, online-only, continuous publication journal. Copyright

Copyright (C) 2019 The Author(s). Published by Wolters Kluwer Health, Inc. on behalf of the American

Academy of Neurology.. All rights reserved. Online ISSN: 2332-7812.

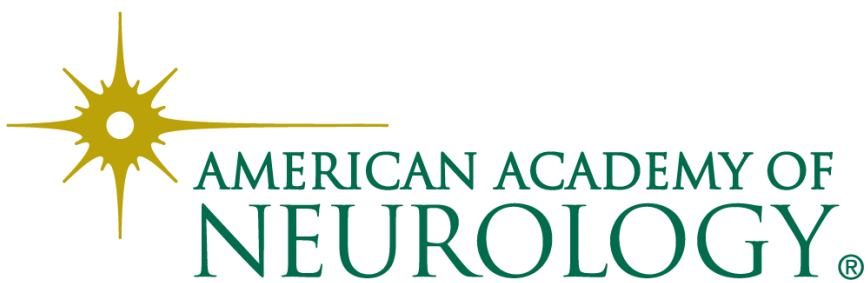

